\title{
Research and Outlook on Global Energy Interconnection
}

\author{
Jun $\mathrm{Li}^{1}$, Zhengxi Chen ${ }^{1}$, Chen Chen ${ }^{1}$, Yangzi Wang ${ }^{1}$, Fulong Song ${ }^{1}$ and Xiaoxiao $\mathrm{Yu}^{1}$ \\ ${ }^{1}$ Global Energy Interconnection Development and Cooperation Organization, Economic and Technology Research Institute, No.8 \\ Xuanwumen Street Xicheng District Beijing, China
}

\begin{abstract}
Currently, the world is confronted with a series of challenges including resource shortage, climate change, environment pollution and energy poverty, which are rooted in the humanity's deep dependence on and large-scale consumption of fossil energy. To tackle with those challenges is an urgent task for realizing sustainable development. The Global Energy Interconnection (GEI) is a clean energy-dominant, electricitycentered, interconnected and shared modern energy system. It is an important platform for large-scale development, transmission and utilization of clean energy resources at a global level, promoting the global energy transition characterized by cleaning, decarbonization, electrification and networking. The GEI has provided a scientific, novel and systematic solution to implement Agenda 2030 as well as the Paris Agreement. Focusing on the scope of clean transition and sustainable development, this paper has implemented qualitative and quantitative methods based on historic data. The global power demand and supply has been forecasted. Based on global clean energy resources endowments and distribution, a global main clean energy bases layout and generation planning optimization has been proposed. Later in this paper, the global power flow under the GEI scenario and corresponding GEI backbone grid has been explored and proposed. Finally, based on a preliminary investment estimation, the comprehensive benefits of building the GEI have been analyzed.
\end{abstract}

\section{Introduction}

In 2020, the COVID 19 virus has caused huge disasters to people all over the world, and it has sounded the alarm: mankind and the planet have entered an era of 'crisisridden'. More urgently, climate change is accelerating its evolution into a global ecological environment crisis.

Climate change is a comprehensive reflection of the interactive effects of the earth system. After the climate system is affected by human activities, it will cause changes in the various layers of the earth system, resulting in complex, interconnected, and global effects, and it is very likely to cause irreversible changes in other layers. From 1980 to 2018, the number of global natural disasters showed a steady upward trend. In 2018, there were more than 800 major natural disasters globally, which quadrupled compared with 1980. In the past 20 years, global natural disasters have caused an average of more than 68,000 lives and 220 million people affected each year. The human social system is becoming more and more complex, and the connection with the natural system is getting closer. A single crisis, social crisis and natural crisis conduct among each other, which can rapidly deteriorate into multiple crises, with more serious consequences. Therefore, the climate and environmental crisis will not only accelerate various natural crises and ecological crises, but also cause social crises such as food shortages and conflicts and wars. It is the biggest potential risk faced by all countries.
Research by Global Energy Interconnection Development and Cooperation Organization (GEIDCO) shows that the development of the climate crisis mainly presents four phases. The first is the risk-controllable stage: climate change reaches or exceeds the $1.5^{\circ} \mathrm{C}$ safety threshold, but the overall risk is still controllable; the second is the threshold breakthrough stage, when climate change exceeds the $2^{\circ} \mathrm{C}$ safety threshold, the ecosystem rapidly deteriorates and the impact is irreversible; the third is temperature rise acceleration phase, climate change has accelerated the emission of greenhouse gases stored in ice caps, frozen soil and oceans into the atmosphere, and the temperature rise suddenly accelerated; fourth is the overall crisis phase, when climate change exceeds the critical threshold of $5^{\circ} \mathrm{C}$, the earth system and human society are facing a full crisis . Once the safety thresholds of $1.5^{\circ} \mathrm{C}$ and $2^{\circ} \mathrm{C}$ are exceeded, the climate system will irreversibly accelerate its temperature rise and enter the 'full crisis' stage.

At present, we are on the fast track of 'full crisis'. Continuing the existing development path is likely to lead to a temperature rise of $3.2^{\circ} \mathrm{C}-5.4^{\circ} \mathrm{C}$, which will cause the earth system to deviate from the normal and stable natural cycle, and its consequences will bring four major disasters. First, the melting of ice sheets triggers the collapse of key climate systems and chain reactions, leading to climate disasters; second, climate and environmental disasters comprehensively trigger polar, terrestrial, freshwater, and marine ecological disasters; third, climate disasters cause sea levels to rise sharply, 
leading to survival disasters; fourth, climate and environmental disasters lead to economic collapse, social unrest, and social disasters. Obviously, the fate of mankind in the future depends to a large extent on our actions to deal with the climate and environmental crisis.

The root of the climate crisis comes from dependence on fossil energy, and the international community already has a broad consensus on this. Mankind's misconceptions and development thoughts are deeply rooted, and the inertia of high-carbon economic development is huge. Global, systematic and implementable solutions are needed to form ideological consensus and joint actions to deal with crises, and accelerate the implementation of clean energy transition and sustainable development. Only by getting rid of the dependence on fossil energy can the risk of crises be reduced fundamentally. In essence, the core of sustainable development is clean development. The key is to promote clean replacement on the energy production side, replacing fossil energy with clean energy such as solar, wind, and hydropower; on the energy consumption side, replacing coal, oil, gas and firewood with clean electricity.

The GEI is a modern energy system which is clean, electricity-centered, interconnected, co-constructible and sharable. It will establish a platform for world-wide largescale exploitation, transmission and utilization of clean energy, promote the global energy transition featured with clean, de-carbonization, electrification and networking. Building the GEI can fully implement the United Nations 2030 Agenda and the Paris Agreement to address climate change, ensure that everyone enjoys clean, reliable, and affordable modern energy, and achieve comprehensive and coordinated economic, social and ecological development. In order to accelerate the development of the GEI, since 2016, GEIDCO has carried out systematic and in-depth research on energy interconnections of the world, continents, key regions and countries. Through extensive research, comprehensive analysis of global economic and social, energy, power, climate and environmental data, GEIDCO has fully studied relevant development strategy plans and policies of government departments of various countries, widely absorbed research results of relevant international organizations, institutions and enterprises, and applied research methods, models and tools to conduct in-depth research on the development vision, path and major issues of the GEI.

Based on the development concept of the GEI and related research results, from a global perspective, this paper deeply analyzes the development trend of the energy interconnections on various continents, and conducts research and prospects on the overall development of the GEI, and proposes systematic and overall innovative solutions under the framework of the GEI, which are of great significance for accelerating the green energy transition, coping with climate change, and achieving sustainable development. The follow-up discussion structure of this article is as follows. Section 2 will introduce the development concept and connotation of the global energy Internet; Section 3 discusses the outlook of the future development trend of energy and power; Section 4 proposes the distribution of large-scale clean energy bases based on the global clean energy resource distribution.; Section 5 proposes the global power flow pattern, the GEI backbone grid and the development direction of continental energy interconnections; Section 6 estimates the comprehensive benefits of building the GEI; finally, in Section 7 provides a comprehensive summary.

\section{Development Concept of the GEI}

Energy is the material basis of economic and social development, and the sustainable supply of energy is the fundamental guarantee of the human sustainable development. Therefore, to address the challenges in achieving sustainable development, the key is to promote clean development and rigorously implement 'Two Replacements, One Increase, One Restore and One Conversion' which aims to build the GEI and accelerate the formation of a modern energy system that is clean, electricity-centered, interconnected, co-constructible and sharable, ensuring clean, safe, affordable and efficient energy can be accessed by all individuals. In this way, we can find a scientific solution to promote global sustainable development through clean energy development.

Two Replacements are to use clean alternatives in energy production, replacing fossil fuels with hydro, solar, and wind energy known as Clean Replacement, and to promote Electricity Replacement in energy consumption, replacing coal, oil, natural gas and firewood with electricity. One Increase in the level of electrification and energy efficiency, increase in the proportion of electric energy in final energy consumption, and reduction in energy consumption on the premise of ensuring energy consumption needs. One Restore to the restoration of fossil energy to its basic attribute as industrial raw material to create greater value for economic and social development. One Conversion means that $\mathrm{CO}_{2}$, water and other substances will be converted to fuels and raw materials such as hydrogen, methane, and methanol and minerals by virtue of electricity to resolve the resource constraints and pave the way for future energy development and sustainable development of mankind.

The essence of building the GEI is the holistic construction of 'Smart Grid + UHV grid + Clean Energy', where smart grid is the foundation, UHV grid is the key and clean energy is the source. By integrating modern intelligent technologies such as advanced transmission, intelligent control, new energy integration and advanced energy storage, a smart grid can adapt to grid connection and accommodation all kinds of clean energy, meet the needs to integrate various intelligent power equipment and provide interactive services, realizing the coordinated development of power source, network, load and storage, multi-energy complementarity and efficient utilization. UHV power grid is composed of $1000 \mathrm{kV} \mathrm{AC}$ and \pm 800 and $\pm 1100 \mathrm{kV} \mathrm{DC}$ systems, with significant advantages including long transmission distance, large capacity, high efficiency, low loss, reduced land occupation and good security. It can realize thousands-of-km and tens-of-GW power transmission and interconnection of transnational and transcontinental 
power grids. With the advancement of conversion technologies and cost reduction of hydro, wind and solar energy, the competitiveness of clean energy will surpass fossil energy in an all-rounded way, accelerating the replacement process of fossil energy and becoming the main source of energy in the future energy system.

The GEI is the fundamental strategy to cope with climate change and achieve the goal of temperature control. The GEI provides a technically feasible, economically sound, operational, statistical and transparent system solution for the world to tackle climate change and implementing the Paris Agreement. During the course of the GEI construction, replacement of carbon-based energy with clean electricity can be promoted to accelerate the process of realizing global carbon emission reduction goals, decouple the economic development with carbon emissions, and comprehensively implement the core targets of the Paris Agreement, such as mitigation, adaptation, capabilitybuilding of financial and technical, and transparency. The $\mathrm{CO}_{2}$ emissions that come from global energy consumption can peak around 2025 and fall to about 10 billion tons by 2050 which is less than half of the 1990 level. By achieving zero net emissions by 2065 , the goal of controlling global temperature rise within $2^{\circ} \mathrm{C}$ by the end of the century could be achieved. By accelerating the construction of the GEI, global clean energy and power interconnection will develop rapidly, which will promote energy system carbon emissions to decline earlier and achieve zero net emissions as early as possible with low negative emissions, and therefore, the temperature control target of $1.5^{\circ} \mathrm{C}$ could be achieved.

\section{Energy and Power Development Trends}

Analysis and forecast on the trends of global energy and power has been carried out for promoting the comprehensive, coordinated and sustainable development of the global economy, society, environment and achieving the $2^{\circ} \mathrm{C}$ temperature control target of the Paris Agreement.

\subsection{Energy Demand}

Global primary energy demand continues to grow. By the partial substitution method, the global primary energy demand in 2035 and 2050 will reach 24.5 and 26.2 billion tons of coal equivalent (tce), respectively. The average annual growth rate is $0.7 \%$ from 2016 to 2050 , of which the rate is about $1 \%$ from 2016 to 2035 and about $0.4 \%$ from 2036 to 2050

The main direction to optimize the global energy structure is to develop clean energy as the dominant source of energy. Around 2025, the total demand of global fossil energy will reach its peak before declining year by year. The global coal demand will peak around 2025, reaching about 5.4 billion tce, before declining to 1.79 billion tce in 2050, accounting for $6.3 \%$ of the total global primary energy demand. The share of clean energy in primary energy will increase from $24 \%$ in 2016 to $70 \%$ in
2050. Before 2040, the share of clean energy will exceed the share of fossil energy and become the main primary energy source.

The increase of global primary energy demand is mainly contributed by Asia. From 2016 to 2050, Asia's primary energy demand is expected to rise by $57 \%$, from 9.5 to 14.9 billion tce, with an average annual growth rate of $1.3 \%$. Asia's share in global primary energy demand continues to increase, from $46 \%$ to $57 \%$. The primary energy demand in Africa and Central and South America will increase by 1.4 and 0.62 billion tce, with an average annual growth rate of $2.3 \%$ and $1.3 \%$, respectively.

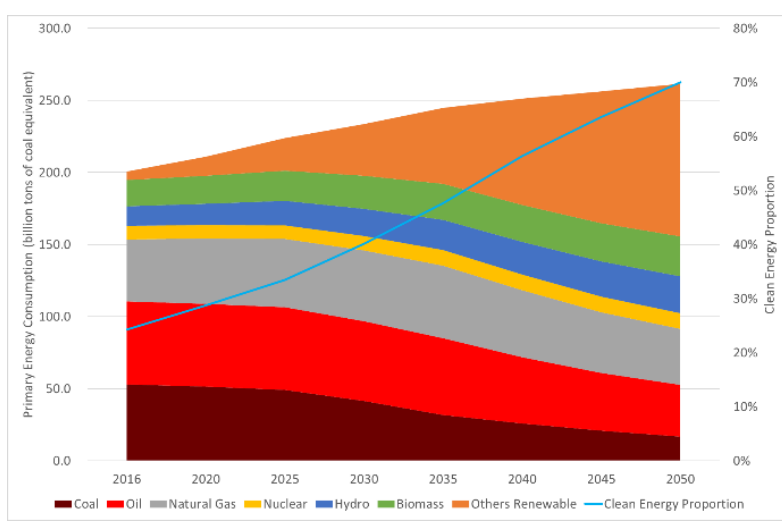

Fig. 1. Primary energy demand forecast under the $2{ }^{\circ} \mathrm{C}$-scenario.

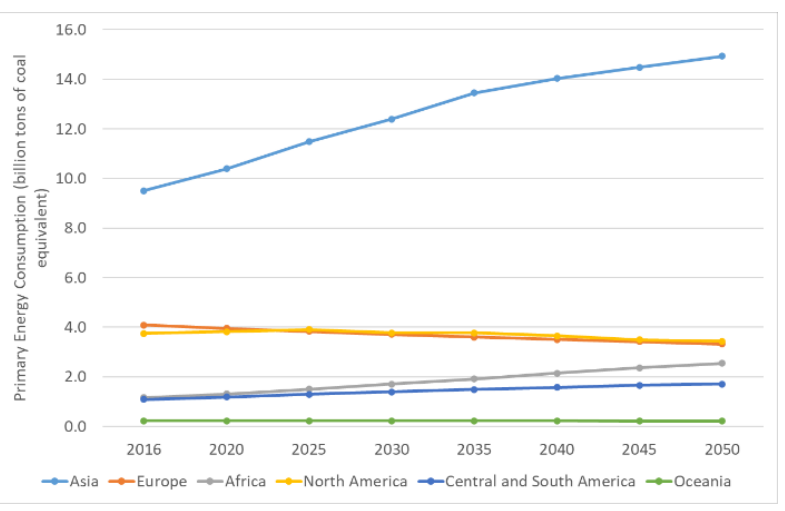

Fig. 2. Continental primary energy demand forecast under the $2{ }^{\circ} \mathrm{C}$-scenario.

Global final energy consumption will peak around 2040. From 2016 to 2040, the global final energy consumption will grow steadily from 13.7 to 16.2 billion tce with an average annual growth rate of about $0.7 \%$. Due to the slowdown of the world economy and the improvement in energy efficiency, the final energy consumption is expected to decline. In 2050, the global final energy consumption will fall to 15.7 billion tce with an average annual decline of $0.3 \%$ from 2040 to 2050 . From 2016 to 2050, the average annual growth rate of final energy will be about $0.5 \%$. The final consumption of fossil energy will drop significantly. From 2016 to 2050, the share of fossil energy in final energy consumption will fall from $63 \%$ to $24 \%$. The final coal consumption will peak at about 1.7 billion tce around 2025, before falling by $63 \%$ to 550 million tce in 2050 . The final oil consumption will remain stable from 2020 to 2035 at around 5.8 billion tce. Thereafter, the consumption will fall rapidly to 3.0 billion tce in 2050 accounting for a 
decrease of $47 \%$ compared to the consumption in 2016. After the natural gas consumption reaches its peak in 2040 , it will drop to about 1.4 billion tce in 2050, accounting for a decrease of about $34 \%$ from the level in 2016. The basic trend of the global final energy structure will be electricity-centered and the share of electricity will increase significantly. The share of electricity in the total final energy consumption is expected to increase from $22 \%$ in 2016 to $54 \%$ in 2050 , and in around 2035, electricity will surpass oil and become the dominant source of energy in the final energy structure.

The share of electricity in final energy consumption will significantly increase in all continents and there will also be an acceleration in the implementation of Electricity Replacement. With the accelerated development of Electricity Replacement technologies such as electric vehicles, electric heating and electricityproduced hydrogen, the energy transition in developed regions such as Europe and North America will accelerate and move towards becoming more electricity-centered in the final energy structure. In 2050, the share of electricity will be $59 \%$ of the final energy in both regions, significantly higher than the global average. Africa will also gradually reduce its dependence on primary bioenergy such as fuelwood, agricultural and forestry wastes, and establish a modern energy system by replacing low-quality energy with electricity.

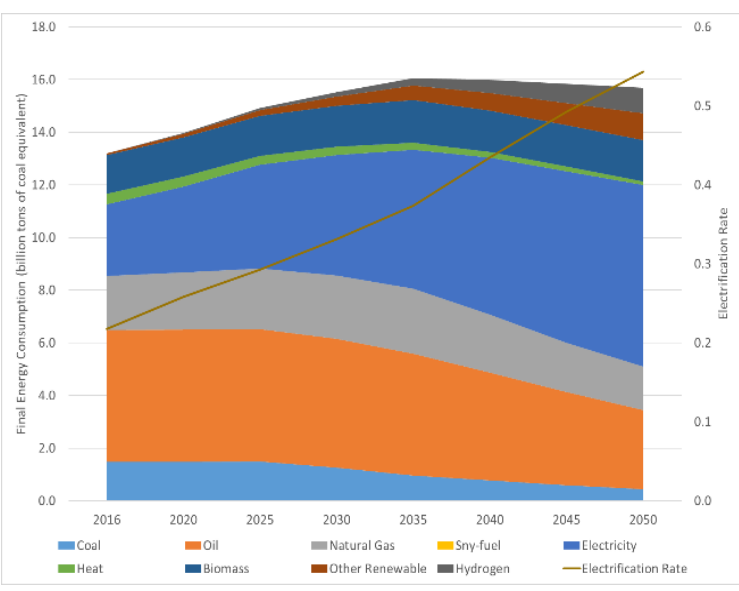

Fig. 3. Final energy demand forecast under the $2^{\circ} \mathrm{C}$-scenario.

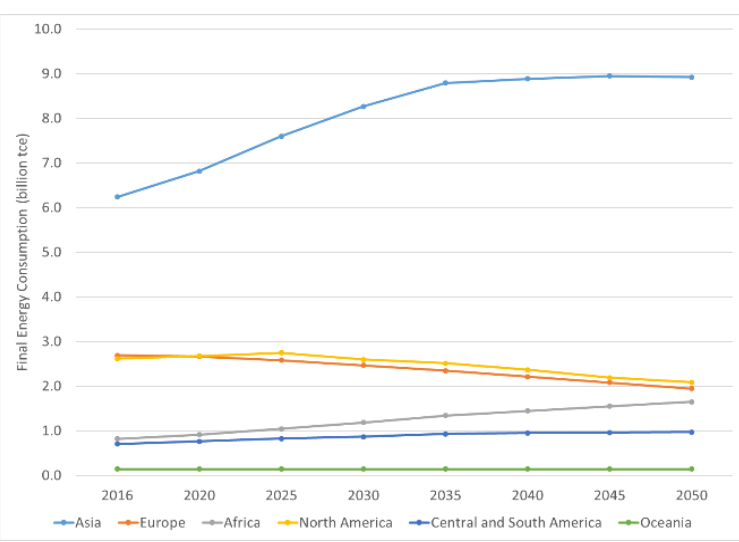

Fig. 4. Continental final energy demand forecast under the $2{ }^{\circ} \mathrm{C}$ scenario.

\subsection{Power Demand}

With the global economic recovery, steady population growth, continuous technological advancement and rapid implementation of 'Two Replacements', the global power demand will generally grow steadily at a high pace in the future.

It is estimated that in 2035, the global electricity consumption will reach $44.1 \mathrm{PWh}$, and the average annual growth rate will be $3.66 \%$ from 2016 to 2035 . In 2050, the global electricity consumption will reach $61.6 \mathrm{PWh}$ with an average annual growth rate of $2.25 \%$. The global electricity consumption per capita will increase from 2985 $\mathrm{kWh}$ in 2016 to $6300 \mathrm{kWh}$ in 2050.

Asia's position as a global power load center will become increasingly prominent. It is estimated that the average annual growth rate of electricity consumption in Asia will be $4.42 \%$ from 2016 to 2035 , and the demand will reach 24.9 PWh which accounts for $58.9 \%$ of the total global power demand. From 2036 to 2050, the increase rate in electricity consumption will be reduced to $2.53 \%$, and the electricity consumption will reach $36.3 \mathrm{PWh}$, accounting for $58.9 \%$ of the global total.

Power demand is growing rapidly in Africa, Central and South America, and their electricity consumptions increasing fastest in the world. There are still a large number of people with no access to electricity in Africa, and the electricity consumption per capita is low at present. Considering the growth of power demand and the Electricity Replacement from industrialization and urbanization, the growth rate of power demand in Africa and Central and South America will reach $6.92 \%$ and $4.92 \%$ from 2016 to 2035 , respectively, and the electricity consumption will increase to $2.27 \mathrm{PWh}$ and $2.65 \mathrm{PWh}$. From 2036 to 2050, Africa's electricity consumption will continue to grow rapidly with an average annual growth rate of $3.79 \%$, and the electricity consumption in 2050 will reach $3.97 \mathrm{PWh}$. The annual average growth rate of electricity consumption in Central and South America will fall to $2.49 \%$, and in 2050 , the consumption will reach 3.83 PWh.

In Europe, North America and Oceania, the electricity consumption per capita will be high and the Electricity Replacement in sectors such as railways, electric vehicles, and clean heating will result in high power demand. The growth rate of mid and long-term power demand is expected to remain $1 \%-3 \%$.

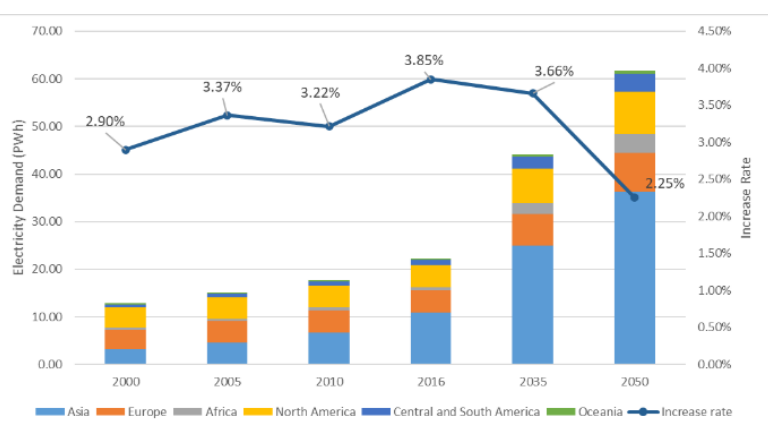

Fig. 5. Electricity demand forecast under the $2^{\circ} \mathrm{C}$-scenario. 


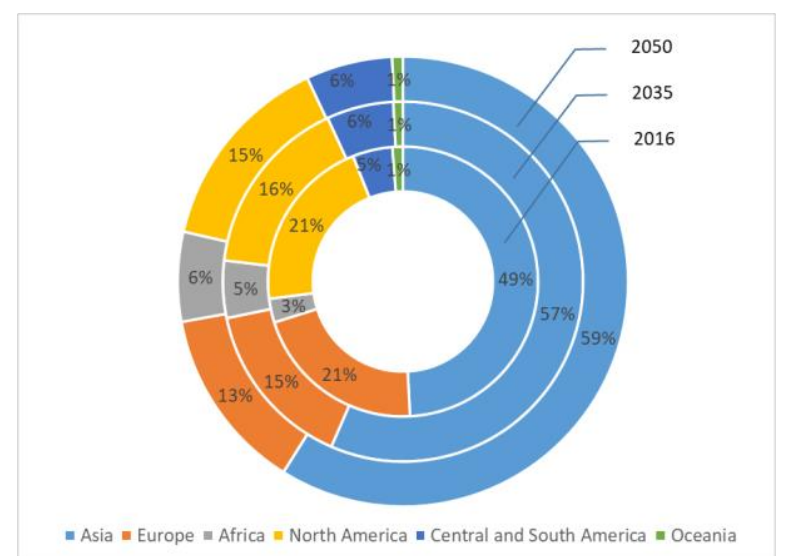

Fig. 6. Continental electricity demand proportion under the $2{ }^{\circ} \mathrm{C}$ scenario.

\subsection{Power Supply}

In order to achieve clean transformation and sustainable development in an optimal way, it is necessary to coordinate the factors such as the consideration of global resource endowments, energy and power demand, energy development costs, land value and environmental carrying capacity and power system operation.

It is estimated that by 2050 , the global installed capacity will be $26 \mathrm{TW}$ with clean energy installed accounting for $84 \%$, among which wind power is $26 \%$, solar power is $42 \%$, hydropower is $11 \%$, nuclear power is $2 \%$, and bioenergy, geothermal and others is $3 \%$. Meanwhile, the installed per capita will have reached 2.7 $\mathrm{kW}$. The global clean energy generation will be $51 \mathrm{PWh}$, accounting for $81 \%$ of the total amount, of which $23 \%$ is wind power, $32 \%$ is solar power, $15 \%$ is hydropower, $6 \%$ is nuclear power, and $5 \%$ is bioenergy, geothermal and others.

Global coal-fired power installed capacity will peak around 2030. In 2016, the global installed capacity of coal-fired power was $2.08 \mathrm{TW}$, and by 2030 , the net increase will have been $310 \mathrm{GW}$, which will basically be at its peak (new coal-fired generating units are mainly in Asia). Subsequently, coal power will gradually decrease to $1.8 \mathrm{TW}$ in 2035 and within $1.3 \mathrm{TW}$ in 2050 .

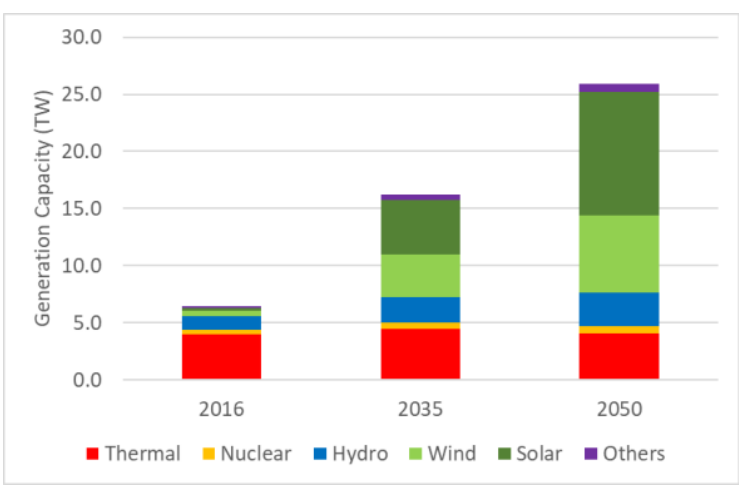

Fig. 7. Generation capacity forecast under the $2{ }^{\circ} \mathrm{C}$-scenario.

In terms of continents, in 2050, the installed capacity of Asia, Europe, Africa, North America, Central and South America, and Oceania will be accounting for $61 \%$,
$15 \%, 5 \%, 14 \%, 5 \%$, and $1 \%$ respectively. The proportion of thermal power installed in Asia will drop from $67 \%$ in 2016 to $16 \%$, from $48 \%$ to $7 \%$ in Europe, from $78 \%$ to $23 \%$ in Africa, from $65 \%$ to $19 \%$ in North America, from $42 \%$ to $16 \%$ in Central and South America, and from $66 \%$ to $32 \%$ in Oceania. The overall installed capacity of hydro, wind and solar clean energy will develop simultaneously. The installed capacity per capita in Asia, Europe, Africa, North America, Central and South America, and Oceania will be $3.05 \mathrm{~kW}, 4.71 \mathrm{~kW}, 0.52$ $\mathrm{kW}, 6.06 \mathrm{~kW}, 2.14 \mathrm{~kW}$, and $3.2 \mathrm{~kW}$, respectively.

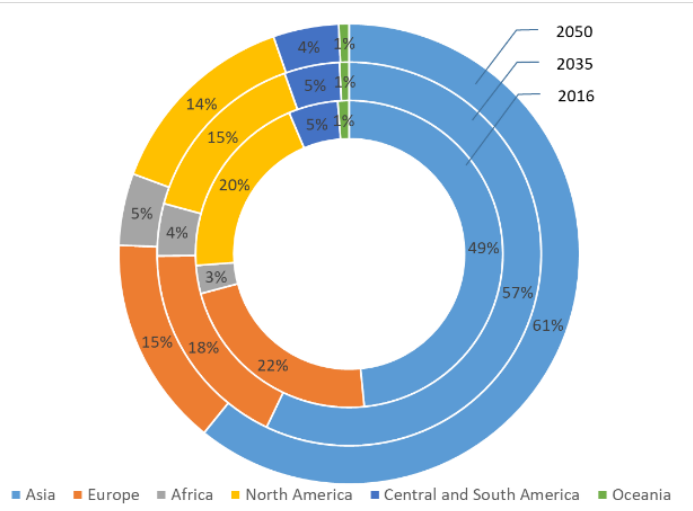

Fig. 8. Continental generation capacity proportion under the $2^{\circ} \mathrm{C}$-scenario.

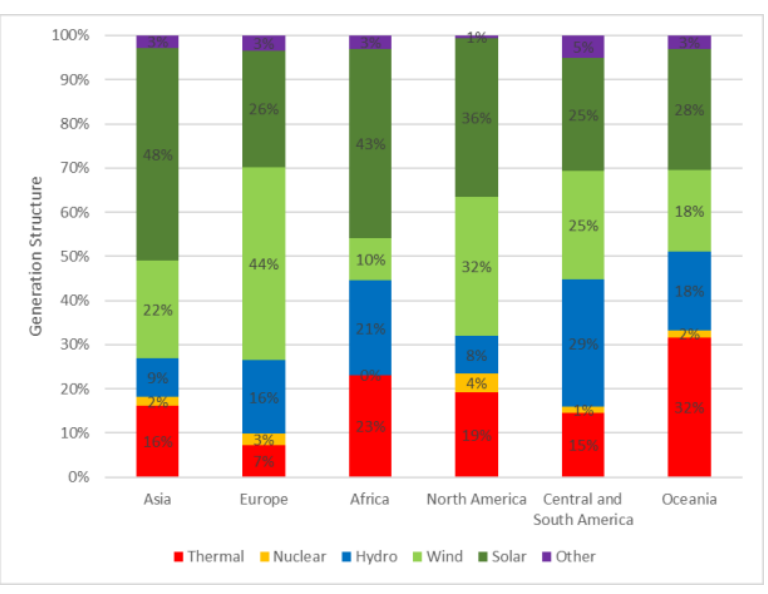

Fig. 9. Continental generation structure under the $2^{\circ} \mathrm{C}$-scenario.

\section{Clean Energy Bases Distribution}

The global clean energy resources, such as hydro, wind and solar energy, are abundant. The theoretical potential of clean energy is higher than $150000 \mathrm{PWh} /$ year. With breakthroughs in clean energy technologies, the economic feasibility of implementing the technologies has been greatly improved, and replacing fossil energy with clean energy is becoming an important trend in the global energy development. Large-scale development and efficient use of global clean energy resources can be achieved through coordinating the distribution and demand of clean energy in either centralized or distributed methods. 


\subsection{Overall Clean Energy Resources}

\subsubsection{Hydro}

The theoretical potential of global hydropower resources is about $39 \mathrm{PWh} /$ year, of which, Asia, Africa, Europe, North America, Central and South America, and Oceania account for $47 \%, 11 \%, 6 \%, 14 \%, 20 \%$ and $2 \%$, respectively.

Table 1. Global hydropower resources.

\begin{tabular}{|c|c|c|}
\hline Region & $\begin{array}{c}\text { Theoretical } \\
\text { potential } \\
\text { (PWh/year) }\end{array}$ & $\begin{array}{c}\text { Global } \\
\text { share } \\
\text { (\%) }\end{array}$ \\
\hline Asia & 18.31 & 47 \\
\hline Africa & 4.4 & 11 \\
\hline Europe & 2.41 & 6 \\
\hline North America & 5.51 & 14 \\
\hline $\begin{array}{c}\text { Central and South } \\
\text { America }\end{array}$ & 7.77 & 20 \\
\hline Oceania & 0.65 & 2 \\
\hline World & 39.06 & 1 \\
\hline
\end{tabular}

\subsubsection{Wind}

The global wind energy resources are abundant, and the annual average wind speed ranges from 2 to $14 \mathrm{~m} / \mathrm{s}$ at the height of 100 meters above the ground. Many regions have an annual wind speed higher than $7 \mathrm{~m} / \mathrm{s}$, and the best wind speed is mainly distributed in Greenland, Denmark, eastern of North America, southern of South America, northern Europe, northern Africa and southern Oceania.

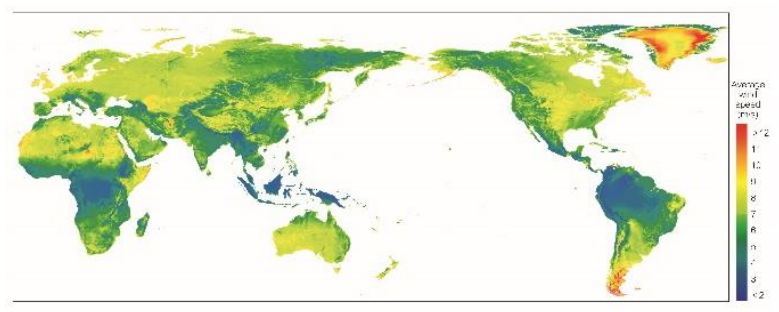

Fig. 10. Distribution of global annual average wind speed.

The theoretical potential of global wind energy resources is about $2050 \mathrm{PWh} /$ year, of which Asia, Africa, Europe, North America, Central and South America, and Oceania account for $24 \%, 32 \%, 7 \%, 21 \%, 11 \%$ and $5 \%$, respectively.

Table 2. Global wind energy resources.

\begin{tabular}{|c|c|c|}
\hline Region & $\begin{array}{c}\text { Theoretical } \\
\text { potential } \\
\text { (PWh/year) }\end{array}$ & $\begin{array}{c}\text { Global } \\
\text { share } \\
\mathbf{( \% )}\end{array}$ \\
\hline Asia & 500 & 24 \\
\hline Africa & 650 & 32 \\
\hline Europe & 150 & 7 \\
\hline North America & 430 & 21 \\
\hline $\begin{array}{c}\text { Central and South } \\
\text { America }\end{array}$ & 220 & 11 \\
\hline Oceania & 100 & 5 \\
\hline World & 2050 & $\backslash$ \\
\hline
\end{tabular}

\subsubsection{Solar}

Solar energy is remarkably rich around the world. The annual global horizontal irradiance (GHI) ranges from 700 to $2700 \mathrm{kWh} / \mathrm{m}^{2}$. The areas with the GHI higher than $2000 \mathrm{kWh} / \mathrm{m}^{2}$ include the sub-Saharan Africa region, the southwestern Africa, Asia and the Middle East, the southern North America, the southwestern South America and the northern Oceania.

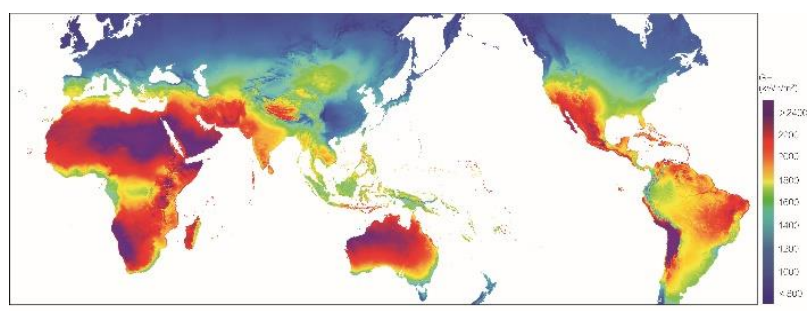

Fig. 11. Distribution of Global Horizontal Irradiance (GHI).

The theoretical potential of global solar energy resources is about $150000 \mathrm{PWh}$ /year, of which, Asia, Africa, Europe, North America, Central and South America, and Oceania account for 25\%, 40\%, 2\%, 10\%, $8 \%$ and $15 \%$, respectively.

Table 3. Global solar energy resources.

\begin{tabular}{|c|c|c|}
\hline Region & $\begin{array}{c}\text { Theoretical } \\
\text { potential } \\
\text { (PWh/year) }\end{array}$ & $\begin{array}{c}\text { Global } \\
\text { share } \\
(\%)\end{array}$ \\
\hline Asia & 37500 & 25 \\
\hline Africa & 60000 & 40 \\
\hline Europe & 3000 & 2 \\
\hline North America & 15000 & 10 \\
\hline $\begin{array}{c}\text { Central and South } \\
\text { America }\end{array}$ & 12000 & 8 \\
\hline Oceania & 22500 & 15 \\
\hline World & 150000 & $\backslash$ \\
\hline
\end{tabular}

\subsection{Distribution of Global Large-scale Clean Energy Bases}

\subsubsection{Large-scale Hydropower Bases}

According to the distribution of global hydropower resources, hydropower bases with large-scale development conditions are mainly distributed in the Jinsha River and the Yarlung Zangbo River in southwestern China, the Mekong River, the Irrawaddy River Basin in Southeast Asia, the Congo River and the Nile River in Africa, the Amazon Basin in South America, Norway, Sweden, etc. There are fifteen large-scale hydropower bases to be developed globally, with the total installed capacity of $880 \mathrm{GW}$ by 2035 and $1.3 \mathrm{TW}$ by 2050. 


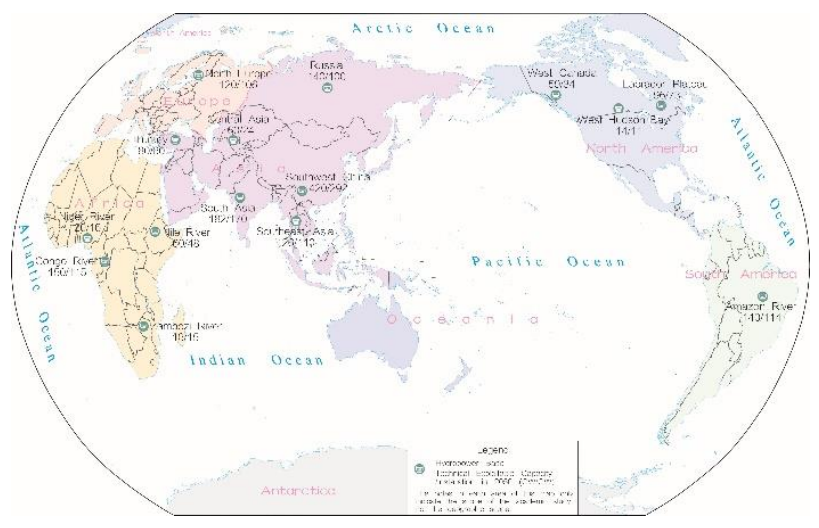

Fig. 12. Distribution and installed capacity of the global large hydropower bases.

\subsubsection{Large-scale Wind Power Bases}

The wind power bases with large-scale development conditions are mainly distributed in Artic regions including Greenland, Sakhalin Island, Okhotsk Sea, etc., as well as in the northwest of China, the North Sea of Europe, the central United States and southern Argentina. There are sixteen large-scale wind power bases to be developed globally, with the total installed capacity of 900 GW by 2035 and 1.49 TW by 2050 .

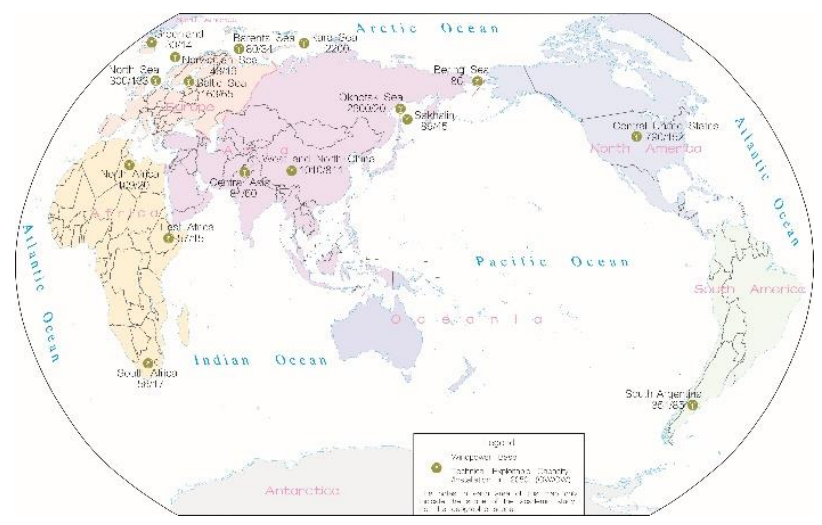

Fig. 13. Distribution and installed capacity of the global large wind power bases.

\subsubsection{Large-scale Solar Power Bases}

According to the distribution of solar energy resources, solar power generation bases with large-scale development conditions are mainly distributed in areas including the northern Africa, the southern Africa, the western Asia, the Central Asia, the western China, the western United States, Mexico, Chile and the northern Australia. There are nine large-scale solar power bases to be developed globally, with the total installed capacity of 1.71 TW by 2035 and 3.82 TW by 2050 .

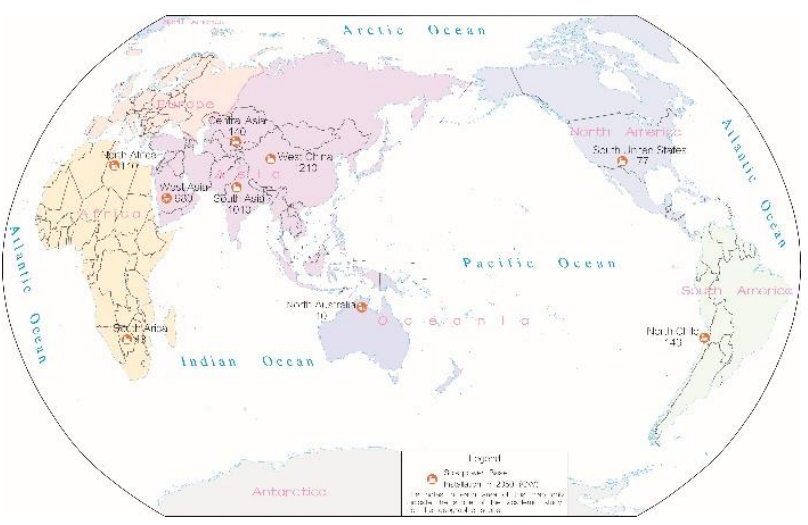

Fig. 14. Distribution and installed capacity of the global large solar power bases.

\subsection{Global Trend of Generation LCOE}

With the rapid development of clean energy power generation technology and the significant reduction in power generation costs, clean energy power generation will gradually replace fossil energy power generation as the dominant power source. As the development and utilization cost of fossil energy and the demand for lowcarbon, clean and safe energy increases, the cost of internal and external input of traditional fossil energy utilization will increase. The scaling effect of clean energy is becoming more and more prominent, where its cost will continue to decrease. As shown in Fig. 15., the LCOE of hydropower will be largely be maintained at 4 US cents/kWh, while in some areas with abundant hydro resources such as the Congo River Basin, it will be kept as low as 3 US cents $/ \mathrm{kWh}$. The LCOE of offshore wind power, onshore wind power, photovoltaics and concentrating solar power all show a downward trend, which will have fallen to $5.5,2.6,1.5$, and 5.3 US cents/kWh by 2050. It is expected that the competitiveness of photovoltaic and onshore wind power will have surpassed coal- and gas-fired power by 2025 .

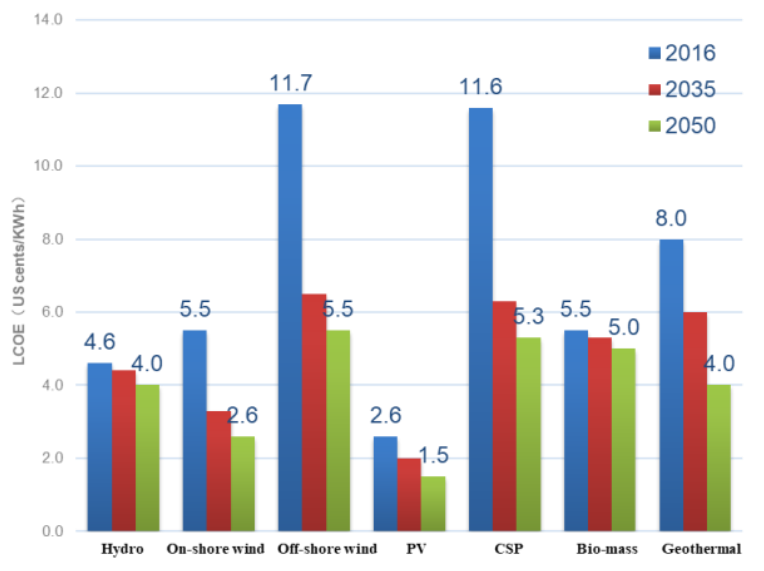

Fig. 15. Global trends in the LCOE of clean energy. 


\section{Development Outlook of Global Energy Interconnection}

\subsection{Global Power Flow Pattern}

According to the principles of green, low-carbon, economic, efficiency, and technical feasibility, and considering the resource endowment and demand distribution, the multi-energy complementarity and largescale mutual support, the local development and longdistance power transmission, the multi-region power optimization model is used to calculate power balance. The balance results of various continents form a power flow pattern with optimal allocation of global resources.

Before 2035, the global power flow will be dominated by cross-border power exchange across continents, and inter-continental power exchange will begin. By 2035, the global inter-continental and inter-regional power flow will reach a total of $330 \mathrm{GW}$, of which, $46 \mathrm{GW}$ will be inter-continental. The inter-regional power flow will mainly run from transmitting hydropower and wind power of Russian Far East and clean energy bases of Central Asia to China, South Korea, Japan and other countries; from the solar bases in West Asia to South Asia India; transmitting hydropower of Central Africa and Eastern Africa to western and southern regions; transmitting hydropower and wind power of Northern Europe to the Continental Europe; transmitting wind power in the mid-western United States and solar power in the southwestern to its eastern regions; transmitting wind power in southern Argentina, solar energy of northern Chile and hydropower of Bolivia to Brazil. Meanwhile, the inter-continental power flow mainly run from the North Africa solar energy bases, the Central Asian clean energy bases and the West Asia solar power bases to Europe; and from the West Asia solar power bases to North Africa Egypt.

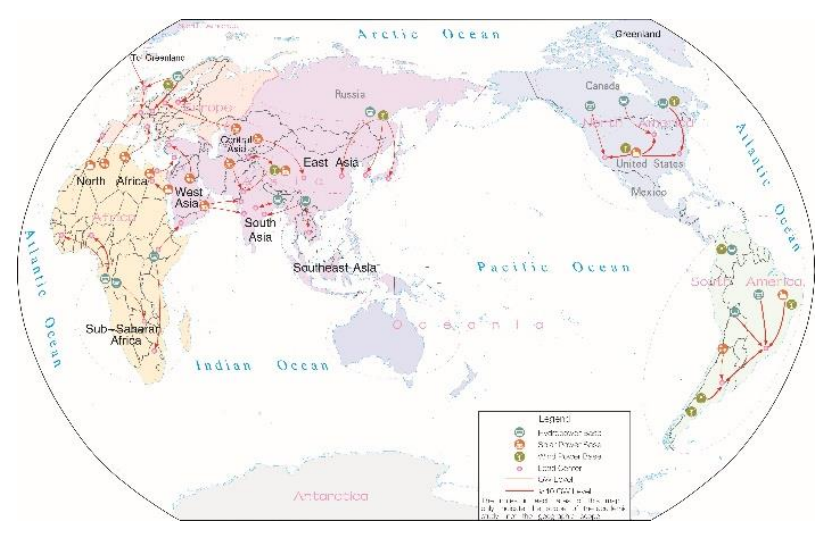

Fig. 16. Illustration of global power flow in 2035.

By 2050, clean energy bases will have entered a largescale development stage, forming a globally optimal allocation of clean energy, multi-energy complementation, and cross-time-zone mutual support. In 2050, the total inter-continental and inter-regional power flow in the world will reach $660 \mathrm{GW}$, of which, the intercontinental power will be $110 \mathrm{GW}$. The inter-regional power flow will run from Russian hydropower and wind power and Central Asia's clean energy bases to China,
South Korea, Japan and other countries with further increase in scale. At the same time, West Asia will send solar power to South Asia; the Arctic wind power bases will send power to China, South Korea and Japan; Central and East Africa will send more power to other African regions; and hydropower in Peru and Bolivia will be sent to Brazil. The inter-continental power flow will mainly run from North Africa solar power bases, Central Asian clean energy bases and West Asia's solar power bases to Europe. With the increasing understanding of the Arctic and breakthroughs in polar transmission technologies, the Arctic region will become an important clean energy base for clean energy worldwide. Power demand of regions such as Asia, Europe and North America will be met through large-scale exploitation of the Arctic wind and Equatorial solar resources.

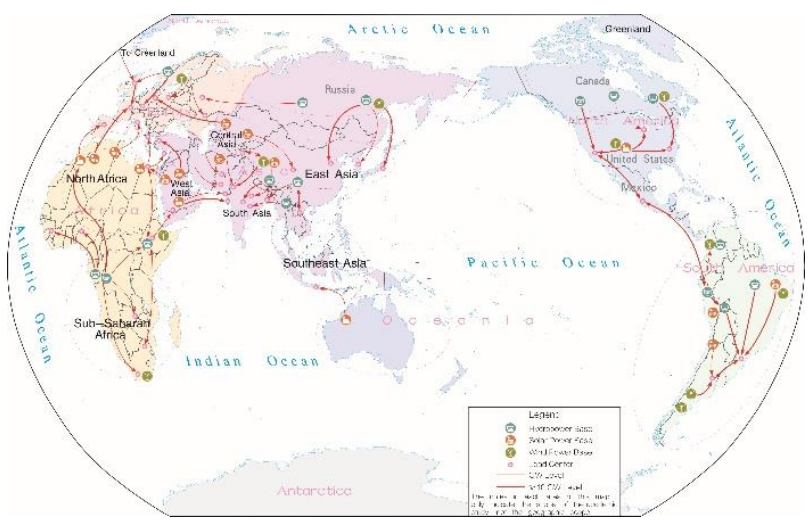

Fig. 17. Illustration of global power flow in 2050.

\subsection{GEI Backbone Grid}

With considerations on the resource endowment, energy $\&$ power demand, and climate \& environmental requirements, the 'Nine Horizontal and Nine Vertical' GEI backbone grid will be constructed based on the national backbone and cross-border interconnection. Large-scale clean energy bases and load centers will be interconnected to achieve clean energy resource allocation globally across different time zones and seasons, providing mutual power support and backup.

The 'Nine Horizontal and Nine Vertical' backbone grid as shown in Fig. 18. includes Asia-Europe-Africa's 'Four Horizontal and Six Vertical' interconnection channels, America's 'Four Horizontal and Three Vertical' channels and the Arctic energy interconnection channel.

\subsubsection{Nine Horizontal Channels}

(1) Arctic Energy Interconnection Channel begins in Norway in Northern Europe, crosses Russia and Bering Strait and stretches all the way to Alaska. The channel crosses 19 time zones and connects $80 \%$ power grids of north hemisphere with a length of $12000 \mathrm{~km}$. The channel achieves mutual power support and backup between continents in an intensive manner.

(2) Asia-Europe North Horizontal Channel interconnects countries such as China, Kazakhstan, Germany, 


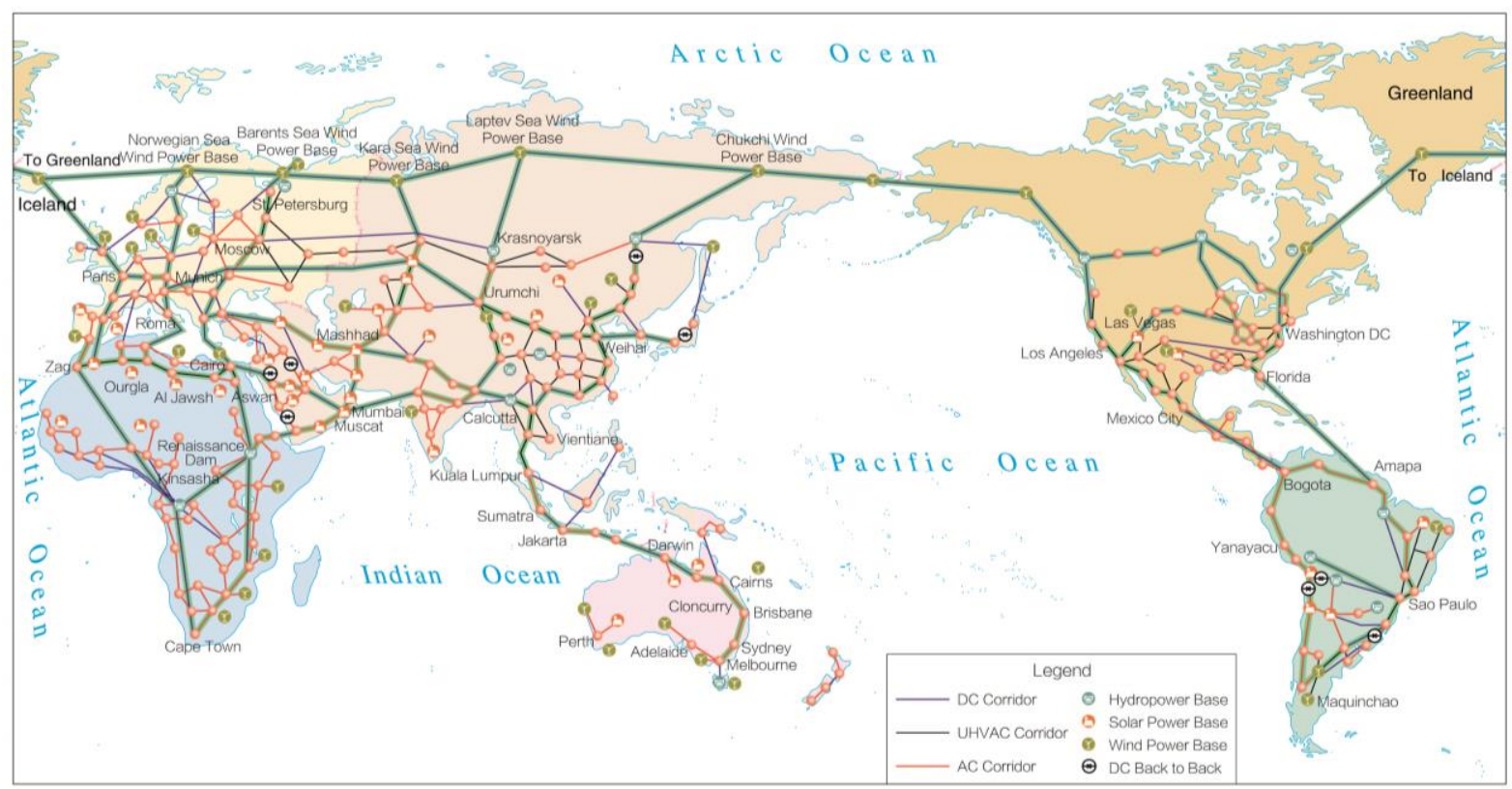

Fig. 18. Illustration of the overall pattern of the GEI backbone grid.

France, and delivers clean energy from Central Asia to Europe and China. Together with the UHV backbone grid of China, clean energy is further delivered to Northeast Asia to provide inter-continental power support. The channel length is $10000 \mathrm{~km}$.

(3) Asia-Europe South Horizontal Channel interconnects Southeast Asia, South Asia, West Asia and Southern Europe, and delivers solar power from the West Asia to load centers in Southeast Europe and South Asia through the UHV DC. The channel also delivers hydropower from Southeast Asia and China to South Asia. The channel length is $9000 \mathrm{~km}$.

(4) Asia-Africa North Horizontal Channel interconnects clean energy bases in Southeast Asia, South Asia and West Asia and North Africa. The channel delivers solar power from the West Asia to Egypt and further delivers to Morocco by the $1000 \mathrm{kV}$ UHV AC. The channel length is $9500 \mathrm{~km}$.

(5) Asia-Africa South Horizontal Channel interconnects hydropower bases of the Congo River, the Nile, and solar power bases of West Asia to provide mutual power support between the African hydropower and the West Asia's solar power. The channel length is $6000 \mathrm{~km}$.

(6) North America North Horizontal Channel interconnects the grids in eastern and western Canada to improve power exchange capabilities, receives the Arctic wind power and delivers to the load centers in eastern Canada. The channel length is $4500 \mathrm{~km}$.

(7) North America South Horizontal Channel gathers the western American solar power, Central American wind power and the Mississippi River hydropower, and delivers to load centers in New York, Washington and western America. The channel length is $5000 \mathrm{~km}$.

(8) South America North Horizontal Channel interconnects the northern countries such as Columbia, Venezuela, Guyana, French Guyana, and Surinam to strengthen the interconnection and power exchange capabilities. The channel length is $3500 \mathrm{~km}$.
(9) South America South Horizontal Channel gathers Peru and Bolivia's hydropower along the Amazon River, along with Chile's solar power, and delivers to load centers in southeastern Brazil. The channel length is 3000 $\mathrm{km}$.

\subsubsection{Nine Vertical Channels}

(1) Europe-Africa West Vertical Channel crosses Iceland, Great Britain, France, Spain, Morocco, West Africa and South Africa, and delivers the Greenland and North Sea's wind power to Continental Europe; and the Congo River's hydropower to the North and South Africa. The North African solar power and Central African hydropower are jointly delivered to the load centers in Europe. The channel length is $15000 \mathrm{~km}$.

(2) Europe-Africa Central Vertical Channel interconnects the Arctic wind power bases, the Northern European hydropower bases and the North African solar power bases, crosses countries including Germany, Austria, Italy, and extends southward to Tunisia. The channel length is $4500 \mathrm{~km}$.

(3) Europe-Africa East Vertical Channel begins from the Barents Sea shore, crosses Russia, Baltic, Ukraine, Balkan Peninsula, Cyprus, Egypt and East Africa to South Africa, and delivers the Arctic and Baltic wind power to Europe, and the Nile's hydropower to the North and South Africa. The Nile hydropower and Egypt solar and wind power are jointly delivered to the Europe. The channel length is $14000 \mathrm{~km}$.

(4) Asia West Vertical Channel interconnects the solar power bases of Central Asia and West Asia and Siberia hydropower bases, gathers multiple forms of energy via the Central Asia synchronous grid, and extends to the Arctic Kara Sea's wind power bases. The channel length is $5500 \mathrm{~km}$. 
(5) Asia Central Channel interconnects the Russian hydropower bases, solar and wind power bases of northwestern China, and hydropower bases of southwestern China, and delivers to the load centers in South Asia through the UHV DC. The channel length is $6500 \mathrm{~km}$

(6) Asia East Vertical Channel interconnects Russia, China, Northeast Asia, Southeast Asia via China and the UHV grids in Southeast Asia, and delivers the clean energy power of Russian Far East, China and Southeast Asia to the load centers, in order to provide power support during the seasons, connect the Arctic wind power bases and extend the channel to Australia in the future. The channel length is $15000 \mathrm{~km}$.

(7) America West Vertical Channel connects the Arctic wind power bases, and constructs a synchronous UHV AC grid around Vancouver, located in the west coast of the U.S., and Mexico. The channel enables efficient utilization of the Canadian hydropower, the U.S. and Mexico's solar and wind power, and interconnects the northern South America's grids through Central America by the UHV DC. This channel extends southward to Chile and enables mutual power support between the North American solar power and South American hydropower. The channel length is $15000 \mathrm{~km}$.

(8) America Central Vertical Channel begins from Manitoba in Canada, crosses the North Dakota and Texas in the U.S., and further extends to Mexico City to form the main UHV vertical channel. The channel collects northern Canada's hydropower and the central U.S.'s wind power to provide mutual power support with multiple forms of energy and cover a wide area of clean energy allocation between the northern and the southern regions. The channel length is $4000 \mathrm{~km}$.

(9) America East Vertical Channel starts from Quebec in Canada, crosses the eastern coast of the U.S. to Florida, forming a main UHV AC vertical channel. This channel connects the northern Canada's hydropower, western U.S.'s solar power and central U.S.'s wind power, traverses across the Caribbean grids, and connects the northern South America grids. This channel further extends to Argentina to provide mutual power support with multiple forms of energy and covers a wide area of clean energy allocation between the northern and the southern regions, as well as connects the Greenland wind power and hydropower. The channel length is $16000 \mathrm{~km}$.

\subsection{Continental Energy Interconnection}

\subsubsection{Asian Energy Interconnection}

The development focus of the Asia power grid will be to accelerate the exploitation and power transmission of large-scale clean energy bases such as South Asia West Asia's solar power, Central Asia's wind power and Southeast Asia's hydropower, transforming these resource advantages into economic advantages, as well as speeding up the construction of power grids in Southeast Asia and South Asia so as to increase electricity accessibility, the interconnection of East Asia for broadening the supply channels of energy and power and maximizing the advantages of the UHV technology, and promoting the inter-continental and inter-regional interconnection, facilitating the direct supply of clean energy from power bases to load centers.

Power flow in Asia is generally featured by power transmission from West to East, North to South. Intercontinentally. Asia will transmit power to Europe, complement with Africa and receive power from Oceania. The power flow will reach $200 \mathrm{GW}$ with $51 \mathrm{GW}$ intercontinental power flow.

In the future, Asia will form an interconnected pattern consisting of five regions: East Asia, Southeast Asia, Central Asia, South Asia and West Asia. In 2050, the Asian energy interconnection will be fully established with 'Four Horizontal and Three Vertical' interconnection channels.

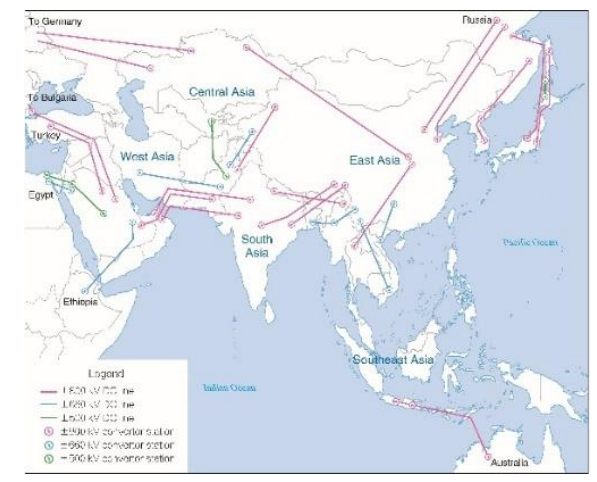

Fig. 19. Illustration of the overall pattern of grid interconnection in Asia.

\subsubsection{European Energy Interconnection}

The development goals of Europe power grid will be to strengthen the construction of domestic transmission channels, thereby improving the access and allocation capacity of renewable energy sources, to improve the level of smart grids, in order to ensure the operational reliability of high-proportion clean energy systems, to strengthen the construction of cross-border transmission channels, to expand the grid interconnection for delivering power from the Baltic and Arctic wind power bases, to take advantage of the 'European Regulatory Power Pool' of the Northern Europe hydropower to realize the mutual power support, to expand intercontinental interconnection, forming interconnection between Asia, Europe and Africa, and to intercontinentally receive clean energy power.

The power flow will render such a pattern as 'intracontinental power transmission from North to South and inter-continental power import from Africa and Asia'. In 2050, inter-continental and inter-regional power flow will reach $133 \mathrm{GW}$, including an inter-continental power flow of $75 \mathrm{GW}$.

In the future, with the upgrade of the power grid and the interconnection scale, Europe will build the European VSC HVDC power grids, connecting the wind power bases of the North Sea, the Baltic Sea, the Norwegian Sea and the Barents Sea, the Northern European hydropower base, and interconnect to North Africa, West Asia and Central Asia inter-continentally. In 2050, a flexible and 
controllable DC grid covering Europe will be formed. The Northern Europe DC grid will be further extended to the Norwegian Sea and the Barents Sea; the DC looped grid will be strengthened in the central Continental Europe, expanding to the Eastern Europe, and forming a DC grid covering Europe; the scale of Asia-Europe-Africa interconnection will be further expanded, and there will be as many as 11 inter-continental DC projects.

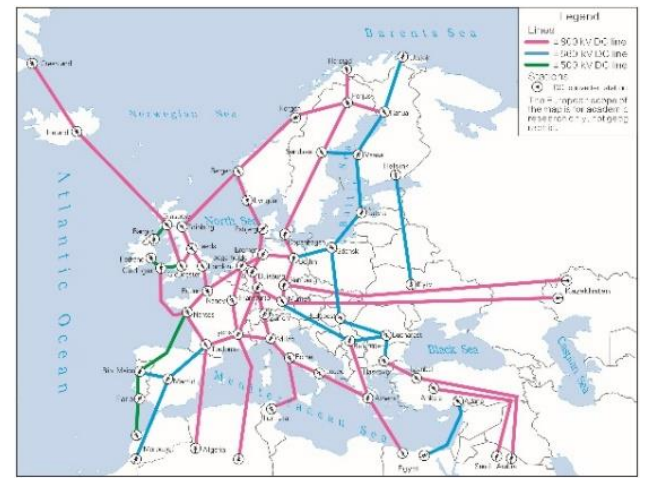

Fig. 20. Illustration of the overall pattern of grid interconnection in Europe.

\subsubsection{African Energy Interconnection}

The development goals of the power grids in Africa will be to strengthen the construction of power grid infrastructure in various countries within the continent, to expand the grid coverage, to improve power supply efficiency and reliability through reinforcement, upgrading and constructing new transmission and distribution grids, to build power transmission channels for large clean energy bases such as hydropower, wind power and solar energy for a coordinated development of clean energy and power grids to meet the power demand from load centers, to accelerate the intra-continental and inter-continental interconnection through exporting clean energy electricity by transforming resource advantages to economic advantages and achieve a wide range and optimal allocation of clean energy.

Form a pattern of 'Central Africa exports power to North and Southern Africa, realizing mutual complementation with Asia and Europe'. In 2050, the total scale of power flow will reach $141 \mathrm{GW}$, of which 54 GW will be inter-continental.

In the future, Africa will have three synchronous grids in the North Africa, Central-West Africa and South-East Africa. In 2050, Africa will build a basic yet strong energy interconnection, forming the 'Two Horizontal and Two Vertical' backbone grid, and expanding the scale of Asia, Europe and Africa interconnection.

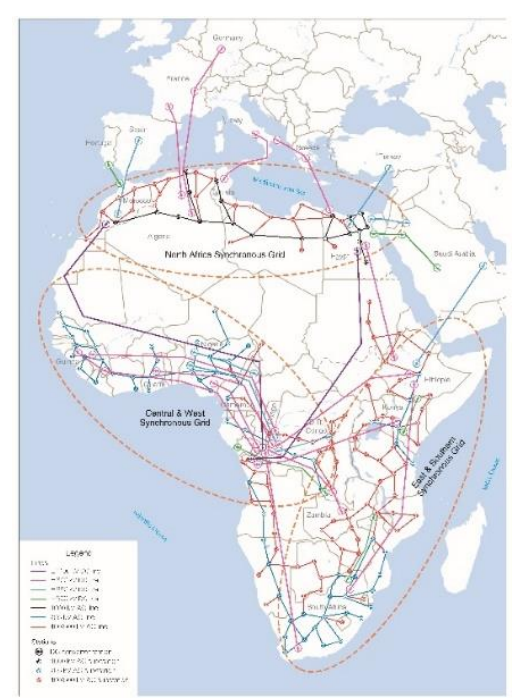

Fig. 21. Illustration of the overall pattern of grid interconnection in Africa.

GEIDCO evaluates the theoretical hydropower potential of the Congo River on its Digital Hydropower Planning Platform. The theoretical hydropower potential in the Congo River are about 2500 TWh per year, accounting for $54 \%$ of the African total amount. According to the comprehensive and coordinative research on river-section hydropower planning, through three-level cascade exploitation, the total installation capacity could reach above $100 \mathrm{GW}$ with an annual generation of about $690 \mathrm{TWh}$.

Hydropower from the upstream and the tributaries of the Congo River will be sent to D. R. Congo, R. Congo, Central African Republic, Cameroon, etc., along the Congo River basin via EHV AC transmission corridors.

Hydropower from the downstream of Congo River, will be sent to the demand centers of more than $2000 \mathrm{~km}$ away via UHV transmission technology. UHV transmission has the advantages of long transmission distance, large capacity, low loss, etc., which enables larger scale hydropower development, transmission and consumption of the downstream Congo River.

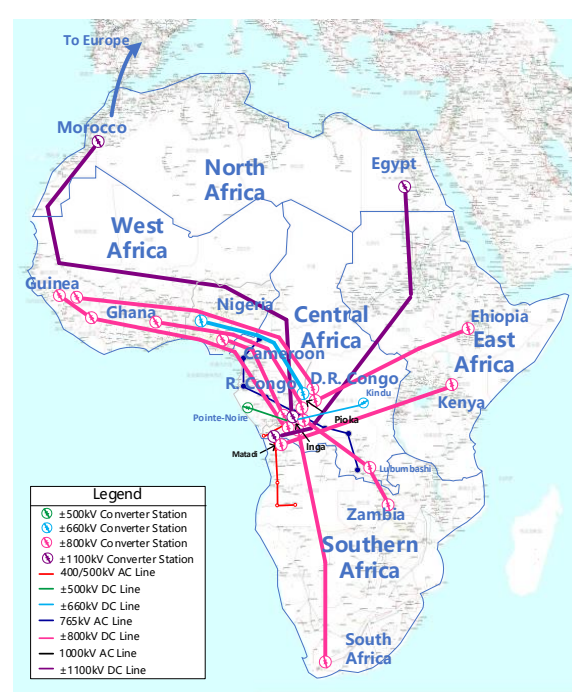

Fig. 22. Overall transmission pattern of the hydropower in the downstream of the Congo River. 


\subsubsection{North American Energy Interconnection}

The development goals of North American power grid will be to accelerate the development and delivery of clean energy bases, and build large-scale clean energy bases such as Canada's hydropower, the Midwest U.S.'s wind power and solar energy, and Mexico's solar energy, in order to achieve coordinated development of clean energy and power grids, as well as building strong North American energy interconnection backbone grids by fully upgrading the existing power grids, so as to strengthen the inter-continental and cross-border interconnection with an interconnected network platform covering large clean energy bases and load centers for an optimal allocation of clean energy.

The overall pattern of power flow in North America will be power transmission from 'north to south, central to coasts, and complementary with Central \& South America through inter-continental power interconnections'. In 2050, The power flow will reach 200 $\mathrm{GW}$, including an inter-continental power flow of $10 \mathrm{GW}$.

In the future, North America will build three synchronous grids in the North America eastern synchronous grid, the North American western synchronous grid and the Quebec grid. In 2050, the North America Energy Interconnection will be fully established, and the UHV AC/DC vertical channel on the east and west coasts and the central clean energy horizontal transmission channel will be built.

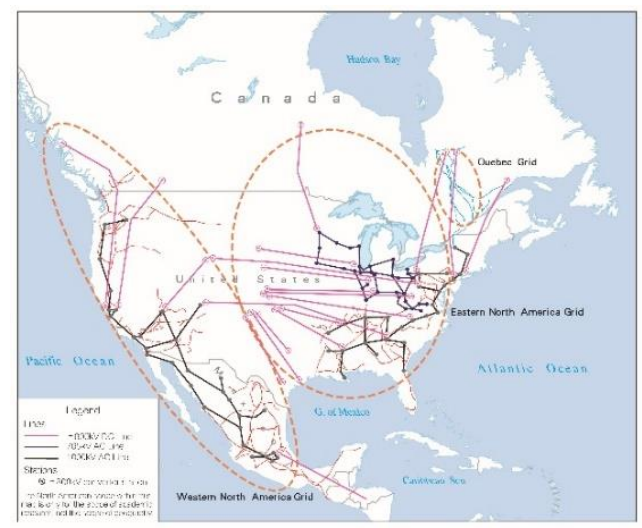

Fig. 23. Illustration of the overall pattern of grid interconnection in North America.

\subsubsection{Central and South American Energy Interconnection}

The development goals of the Central and South America power grid will be to rigorously develop inter-regional and cross-border interconnection, to support the exploitation of hydropower, to actively develop nonhydro clean energy, to achieve large-scale development of clean energy and complementarity, and to meet the economic needs of sustainable economic and social development.

The power flow features hydropower transmission from North to South, wind power transmission from South to North, solar power transmission from West to East, and inter-continental power mutual support with North
America'. By 2050, the total amount of inter-continental and inter-regional power flow will exceed $73 \mathrm{GW}$, of which $10 \mathrm{GW}$ are inter-continental and inter-regional.

In the future, in addition to the Caribbean region, Central and South America will form an overall pattern of three synchronous grids in eastern South America, southern South America, western South America, and Central America. The Caribbean will achieve power exchange or DC cross-island networking. In 2050, the Central and South American Energy Interconnection will maintain the overall pattern of having three synchronous grids, thereby achieving the interconnection to the North America grid.

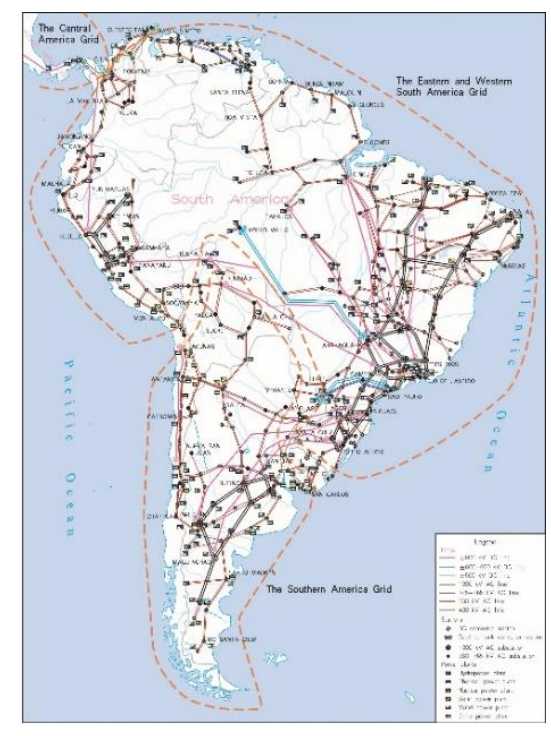

Fig. 24. Illustration of the overall pattern of grid interconnection in Central and South America.

\subsubsection{Oceania Energy Interconnection}

The development goals of Oceania's power grid will be to support the large-scale exploitation, complementation and utilization of solar, wind and hydro power through intercontinental, cross-border and domestic interconnection, in order to realize the transition of clean energy and promote the sustainable development of economy and society. Fiji and other island countries will focus on the construction of domestic transmission and distribution grids, and microgrids to support the exploitation of distributed clean energy generation.

The hydropower of Papua New Guinea shall complement with the solar energy of Australia, and the solar energy of Australia will complement with the seasonal hydropower of Southeast Asia. In 2050, The power flow will reach $10 \mathrm{GW}$, including an intercontinental power flow of $8 \mathrm{GW}$.

In the future, Oceania will construct five synchronous grids in the eastern Australia, western Australia, northern New Zealand, southern New Zealand, and Papua New Guinea, and the power reliability and supply capacity will be further enhanced. In 2050, Oceania will continue to maintain the pattern of five major synchronous grids in the eastern and western Australia, New Zealand's South and North Island, and Papua New Guinea. The power 
exchange between Papua New Guinea and Australia will further be enhanced.

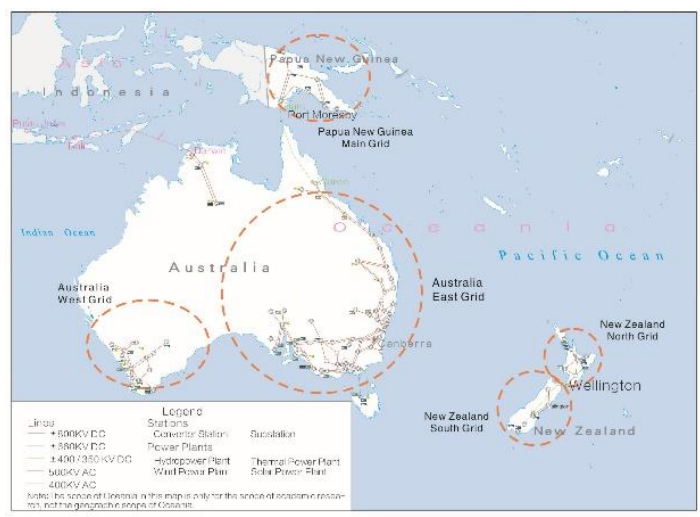

Fig. 25. Illustration of the overall pattern of grid interconnection in Oceania.

\section{Comprehensive Benefits}

\subsection{Investment Estimation}

The investments for GEI power source and grids will be estimated based on the trends in power supply, grid technology development and cost levels. By 2050, the GEI backbone grid will have an increased channel length of $202000 \mathrm{~km}$ and transmission capacity of $660 \mathrm{GW}$, including $11000 \mathrm{~km}$ of submarine cables and $120 \mathrm{GW}$ of submarine transmission capacity, with an estimated total investment of 509.8 billion USD.

With considerations in the different cost levels of power supply and grid investment of the various continents, the amount of investment needed for the various power sources and voltage grade grids in various continents is estimated. From 2019 to 2050, the total investment in GEI is estimated to about 34 trillion USD, of which, the power investment is about 24 trillion USD, and the power grid investment is about 10 trillion USD.

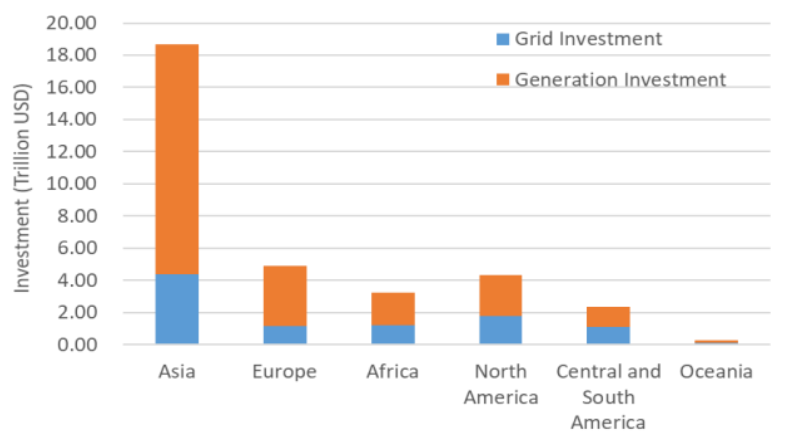

Fig. 26. Total investment estimation of GEI.

\subsection{Benefits Estimation}

It is of great importance to accelerate the development and utilization of clean energy, meet the global power demand, stimulate the world economic growth, reduce the price of electricity, cope with climate change, protect and improve the ecological environment, create a better life for the society and support the building of a community of common destiny for all mankind by building the GEI and the national energy interconnections. Considering the $2^{\circ} \mathrm{C}$-scenario, the following benefits have been estimated.

(1) The power demand can be met by using clean energy. Clean energy will account for more than $70 \%$ of primary energy, and clean energy will account for $81 \%$ of total global power generation in 2050 .

(2) With clean energy, the world economic growth will be further promoted. The total investment on GEI will reach about 34 trillion USD, with the average contribution rate of $2 \%$ to the global economic growth.

(3) Cost of energy supply can be reduced. Clean energy resources will be developed in a large scale and allocated optimally, which will effectively reduce the cost of energy supply. In 2050, the average LCOE of global clean energy will be around $40 \%$ lower than that of 2016 .

(4) The issue of climate change will be effectively addressed with the help of clean energy. Energy system emissions will further drop to about 10.9 billion tons of $\mathrm{CO}_{2} /$ year in 2050, and the temperature control target of $2{ }^{\circ} \mathrm{C}$ of the Paris Agreement will be achieved. Around 2065 , zero net emissions of $\mathrm{CO}_{2}$ from energy use will be achieved.
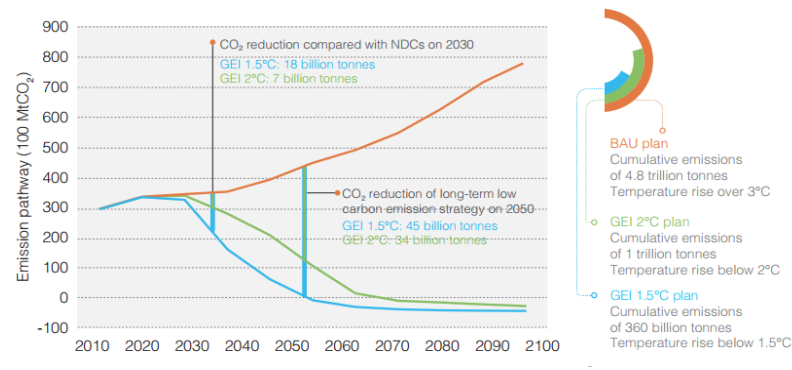

Fig. 27. GEI carbon-emission roadmap.

(5) Clean energy can also protect and improve the ecological environment. By 2050, annual $\mathrm{SO}_{2}$ emissions will be reduced by 50.7 million tons, annual $\mathrm{NO}_{\mathrm{x}}$ emissions by 78.1 million tons, and annual fine particulate matter emissions by 11.43 million tons. The scale of fossil energy development and utilization will be greatly reduced, in terms of mining, processing, transport, storage, combustion, etc. Groundwater pollution, geological damage, terrestrial and marine ecological damage that are brought about by the process will be increasingly reduced, and the ecological environment will be protected and restored.

(6) Clean energy can create a better life in the society. With the sharp decline in electricity prices, green and clean electricity will be made affordable, and the problem of human populations living without electricity will be solved effectively. The number of diseases and death cases caused by pollution will be reduced significantly with reduction of 8 to 10 million related disease cases every year. In 2050, more than 300 million jobs will be created globally. Areas that are rich in resources such as Africa will be able to make use of this advantage and turn it into economic advantages, which will effectively promote economic development and solve poverty issue. 


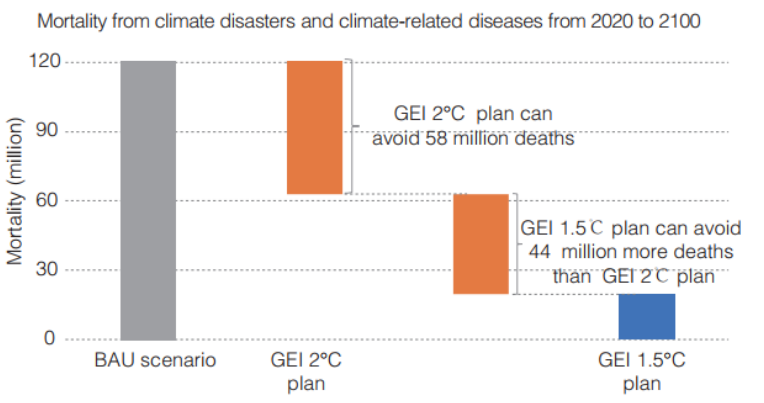

Fig. 28. Diseases reduced under GEI.

\section{Conclusion}

The GEI is a systematic plan of accelerating global energy transition and realizing economic, social, environmental development in a coordinative and sustainable way. To realize the UN 2030 Agenda and Paris Agreement, under the $2{ }^{\circ} \mathrm{C}$-scenario, by 2025 the global fossil energy in primary energy consumption will reach its peak; by 2040 the clean energy will surpass fossil energy and become dominated in primary energy consumption; around 2040, the total final energy consumption will peak and by 2050 , $54 \%$ of the total final energy consumption will be electricity. The potential from electrification will be stimulated and released, by 2050 the global electricity consumption will reach beyond $62 \mathrm{PWh}$ with its annual growth rate of about 3\%, which is more than 3 times that of energy demand. To provide green and sustainable power supply, the global clean energy installed capacity will surpass fossil energy around 2030; by 2050, $84 \%$ of the total capacity will be clean energy generation. Through constructing the 'Nine Horizontal and Nine Vertical' GEI backbone grid, clean energy bases and load centers will be closely connected to achieve global allocation and share of clean energy in a wide range, to ensure clean, safe, economic and efficient supply of energy and power, effective address climate change and protect ecological environment. The total investment of building the GEI is estimated to about 34 trillion USD, through which comprehensive climate, environmental, economic and social benefits can be achieved.

\section{References}

1. Liu Zhenya. Global Energy Interconnection (China Electric Power Press, Beijing, 2015)

2. GEIDCO. Research and Outlook on Global Energy Interconnection (China Electric Power Press, Beijing, 2019)

3. Clark W. Gellings, A Global-Spanning Supergrid. N, IEEE Spectrum, 49-54 (2015)

4. Spyros Chatzivasileiadis, Damien Ernst, and Goran Andersson. The Global Grid. Renewable Energy. J, 57, 372-383 (2013)

5. M. Hasanuzzaman, Ummu Salamah Zubir, Nur Iqtiyani Ilham, and Hang Seng Che. Global Electricity Demand, Generation, Grid System, and
Renewable Energy Policies: A Review. J, WIREs Energy Environ, 6, e222 (2017)

6. Liang Xuming. Application and Research of Global Grid Database Design based on Geographic Information. J, Global Energy Interconnection, 1(1), 87-95 (2018)

7. Zhou Xiaoxin, Lu Zongxiang, Liu Yingmei, Chen Shuyong. Development Models and Key Technologies of Future Grid in China. J, Proceedings of the CSEE, 34(29), 4999-5008 (2014)

8. Zhao Qingbo, Zhang Zhenglin, Bai Jianhua, Zhang Lin, Cheng Lu, Xin Songxu. Theory Innovation and Practice of Electric Power System Planning based on Ultra High Voltage Transmission Technology. J, Proceedings of the CSEE, 34(16), 2523-2532 (2014)

9. Thomas Hammer, Rene Wimmer, Karsten Loppach, Ronny Fritsche. Testing Methods for 1100 kV UHVDC Transformer. J, Global Energy Interconnection, 1(2), 103-107 (2018)

10. K. Adam, M. Müller-Mienack, M. Paun, G. Sanchis, K. Strunz. e-Highway 2050-The ENTSOE facilitated study programme towards a Modular Development Plan on pan-European Electricity Highways System 2050. Cc IEEE PES General Meeting (2012)

11. Menatalla O. Dessouky. The Environmental Impact of Large Scale Solar Energy Projects on the MENA Deserts: Best Practices for the DESERTEC Initiative. C, IEEE Eurocon (2013)

12. UN. World Population Prospects : The 2017 Revision (2017)

13. IEA. World Energy Outlook 2017 (2017)

14. BP. BP Energy Outlook 2017 (2017)

15. BNEF. New Energy Outlook 2018 (2018)

16. Carlos de Castro, Margarita Mediavilla, Luis Javier Miguel, and Fernando Frechoso. Global Solar Electric Potential: A Review of Their Technical and Sustainable Limits. J, Renewable and Sustainable Energy Reviews, 28, 824-835 (2013)

17. Xi Lu, Michael B. McElroy and Juha Kiviluoma. Global Potential for Wind-Generated Electricity. J, Proc. Natl. Acad. Sci. USA. 106, 10933-10938 (2009)

18. Francisco Manzanoagugliaro, Alfredo Alcayde, Francisco G Montoya, Antonio Zapatasierra, and Consolarcion Gil. Scientific Production of Renewable Energies Worldwide: An Overview. J, Renewable and Sustainable Energy Reviews, 18, 134-143 (2013)

19. Y. Zhou, M. Hejazi, S. Smith, J. Edmonds, H. Li, L. Clarke, K. Calvin and A. Thomson. A Comprehensive View of Global Potential for Hydrogenerated Electricity. J, Energy \& Environmental Science, 8, 2622-2633 (2015) 
20. Liu Zhenya, Zhang Qiping, Dong Cun, Zhang Lin, Wang Zhidong. Efficient and Security Transmission of Wind, Photovoltaic and Thermal Power of LargeScale Energy Resource Bases Through UHVDC Projects. J, Proceedings of the CSEE, 34(16), 25132522 (in Chinese) (2014)

21. Xiao Jinyu, Zhang Yu, Wan Lei, Li Huiling. Application of DC Grid in Global Energy Interconnection and Case Study. J, Global Energy Interconnection, 1(1), 32-38 (in Chinese) (2018)

22. IEA. Electricity Information 2015 (2018)

23. EIA. International Energy Statistics 2016 (2018)

24. World Meteorological Organization. Global Wind Energy Database (2016)

25. Huang Kun, Zhou Yuanbing, Qu Haoyuan, Guan Xiupeng, Gao Guowei, Chen Fu. The Study on Cross-Border and Cross-Continent Electricity Trading Mechanisms. J, Global Energy Interconnection, 1(3), 235-241 (in Chinese) (2018) 